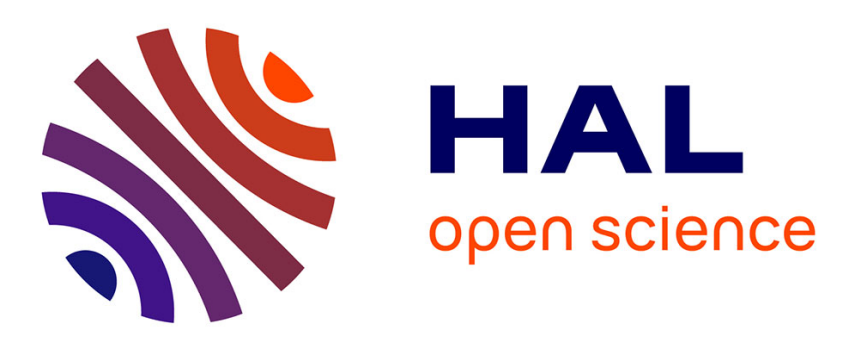

\title{
Numerical Simulation of a Non-Linear Coupled Fluid-Structure Problem With Implicit and Explicit Coupling Procedures
}

Jean-François Sigrist, Driss Abouri

\section{- To cite this version:}

Jean-François Sigrist, Driss Abouri. Numerical Simulation of a Non-Linear Coupled Fluid-Structure Problem With Implicit and Explicit Coupling Procedures. ASME 2006 Pressure Vessels and Piping/ICPVT-11 Conference, Jul 2006, Vancouver, France. 10.1115/PVP2006-ICPVT-11-93107. hal-01911095

\section{HAL Id: hal-01911095 \\ https://hal.science/hal-01911095}

Submitted on 2 Nov 2018

HAL is a multi-disciplinary open access archive for the deposit and dissemination of scientific research documents, whether they are published or not. The documents may come from teaching and research institutions in France or abroad, or from public or private research centers.
L'archive ouverte pluridisciplinaire HAL, est destinée au dépôt et à la diffusion de documents scientifiques de niveau recherche, publiés ou non, émanant des établissements d'enseignement et de recherche français ou étrangers, des laboratoires publics ou privés. 


\section{NUMERICAL SIMULATION OF A NON-LINEAR COUPLED FLUID-STRUCTURE PROBLEM WITH IMPLICIT AND EXPLICIT COUPLING PROCEDURES}

\author{
Jean François SIGRIST \\ Service Scientifique et Technique \\ DCN Propulsion \\ 44620 LA MONTAGNE, France \\ jean-francois.sigristedcn.fr
}

\author{
Driss ABOURI \\ CD-adapco \\ 31, rue Delizy \\ 93698 PANTIN Cedex, France \\ driss.abouriefr.cd-dapco.com
}

\begin{abstract}
The present paper deals with the numerical simulation of a non-linear coupled fluid-structure problem with finite element/finite volume coupled technique and mainly focus on the time coupling algorithm: the coupling procedure lies on a staggered explicit or implicit strategy.

A simple coupled case is studied; namely a non-linear elastic beam coupled with an incompressible fluid with tree surface effects. The structure problem is solved with a finite element approach. The nonlinear discrete structure problem is inlegraled in lime with the nonlinear Newmark scheme with a fixed-point procedure. The fluid problem is solved with a finite volume approach. The non-linear discrete fluid problem is solved with the PISO (Pressure Implicit by Splitting Operator) algorithm. The coupled problem is solved with two different approaches.
\end{abstract}

At first, an explicil approach is proposed, based on a step by step altemate integration of the structure and fluid non-linear problems. As expected the method is found to be numerically dissipative and potentially unstable. An implicit approach is then proposed, using inner coupling iterations. The proposed algorithm is proved to be stable and less dissipative.

Implicit and explicit approaches are presented. Numerical calculations are perlormed on the elementary studied case. Results are presented and compared for the two time-integration procedisres, highlighting the numerical qualities of each prucedure in terns of numerical damping, stability and precision.

\section{INTRODUCTION}

The present paper deals with the numerical simulation of coupled fluid-structure problem, in which the coupling process is based on mechanical exchanges between each sub-problem. In the present study other fluid-structure coupling phenomena, such as therrnal effect, are not taken into account. At the fluid structure interface, fluid and structure are coupled via fluid forces and structure displacement, as sketched by Fig. I.

Over the past years many numerical methods have been developed in order to solve linear and non-linear coupled fluid-structure problems [13] [14].

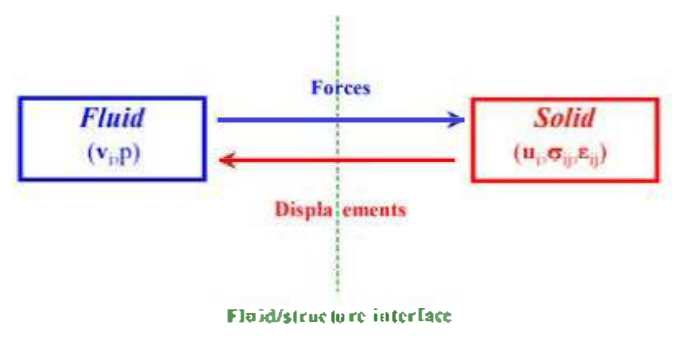

Figure 1. Mechanical fluid-structure coupling

Nowadays, the numerical approach tend to propose general coupling algorithms with specific solvers for each subproblems, with various coupling strategies [4] [7] [15] [17], depending on the physical coupling phenomenon.

As the numerical design naval propulsion structures needs taking fluid-structure interaction into account, DCN Propulsion launched an R\&D study in order to apply numerical methods on industrial projects. From the academic point of view, the coupling process seems not to pose any particular difficulties. From the industrial point of view, an investigation of the various aspects of the numerical fluidstructure coupling on a simple case is necessary before considering a full-scale coupling with existing commercial codes for industrial structure design.

The present study focuses on implicit and explicit coupling procedures for non-linear fluid-structure problems with the view to comparing the two approaches from numerical accuracy and stability points of view. 
The case under study is first presented: explicit and implicit coupling procedures are then exposed. Numerical results are discussed for a linear single degree of freedom and for the non-linear multi-degrees of freedom problems.

\section{A NON-LINEAR FLUID-STRUCTURE PROBLEM}

\subsection{Problem geometry and dynamic equation}

The fluid-structure coupled problem studied in the present paper is described by Fig. $2^{1}$ bellow.

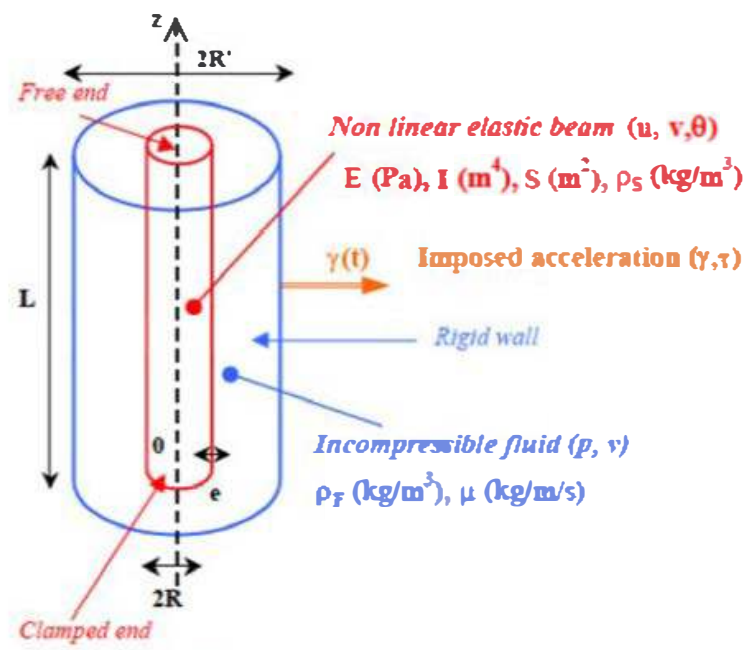

Figure 2. 1D structure-3D fuid non-linear coupled problem

The structure problem is described by the following beam non-linear equation of motion. taking into account geometrical non-linearity [10] [18]. The coupled tractionbending equation of motion are formulated in the relative frame as:

$$
\begin{gathered}
\rho_{s} S \frac{\partial^{2} u}{\partial t^{2}}+\frac{\partial}{\partial z}\left\{E S\left[\frac{\partial u}{\partial z}+\frac{1}{2}\left(\frac{\partial v^{\prime}}{\partial z}\right)^{2}\right]\right\}=0 \\
\rho_{s} S \frac{\partial^{2} v}{\partial t^{2}}+\frac{\partial^{2}}{\partial z^{2}}\left(E I \frac{\partial^{2} v}{\partial z^{2}}\right)-\frac{\partial}{\partial z}\left\{E S\left[\frac{\partial u}{\partial z}+\frac{1}{2}\left(\frac{\partial v}{\partial z}\right)^{2}\right] \frac{\partial v}{\partial z}\right\}=-\rho_{s} S \gamma
\end{gathered}
$$

I he boundary conditions are:

$$
u_{z=0}=0 \quad v_{z=0}=0 \quad \frac{\partial v}{\partial z}=0
$$

\footnotetext{
${ }^{1}$ It is an exiension in the $3 D$ case of the non-linear 20 problem studied in a previous publication, this elementary case beer snedied with an explicit cotpling procedure [18]. The present strdy aims at using the inplicit procedures doviloped by Abouri \& al. for a fuid-rigid body. șistem [1].
}

for the beam clamped end. and:

$$
\left(\frac{\partial u}{\partial z}+\frac{1}{2}\left(\frac{\partial v}{\partial z}\right)^{2}\right)_{=I}=0 \quad \frac{\partial^{2} v}{\partial z^{2}=L}=0 \quad \frac{\partial^{3} v}{\partial z^{3}=L}=0
$$

for the beam free end.

The fluid problem is described by the general NAVIER-STOKES equations. The conservation equations are integrated over a moving control volume $\Omega(r)$ of boundary $a \Omega(t)$, using the LIEBNIrZ rule and the GALSs theorem. This leads to the global conservation equation over an arbitrary control volume [8] in ALE (Arbitrary Lagrangian Eulerian) formulation [16]:

- Mass conservation

$$
\frac{d}{d t}\left(\int_{\Omega(r)} \rho d \Omega\right)+\int_{\alpha(r)} \rho\left(v,-v^{*}\right) d n_{s}=\int_{\Omega(r)} S_{p} d \Omega
$$

- Momentum conservation

$$
\begin{aligned}
& \frac{d}{d t}\left(\int_{\Omega(t)} \rho v_{t} d \Omega\right)+\int_{c \Omega(t)} \rho v_{i}\left(v_{j}-v_{j}^{*}\right) d n_{j}= \\
& -\int_{\infty(t)} p d n_{j}+\int_{\alpha \Omega(t)} \mu\left(\frac{\partial v_{i}}{\partial x_{j}}+\frac{\partial v_{j}}{\partial x_{i}}\right) d n_{j}+\int_{\Omega(t)} S_{n_{j}} d \Omega
\end{aligned}
$$

In Eqs. (5) and (6). $S_{\rho}$ and $S_{v_{j}}$ stand respectively for mass and momentum sources: the fluid problem can then be formulated in the moving frane. The fluid unknowns are the pressu e and velocity fields $p . v_{i}$. but as the conservation equation are integrated orer a moving control volume. Eqs. (5) and (6) show another unknown fluid that is the grid velocity $v_{i}{ }^{\circ}$ : another equation has to be used to close the fluid problem. This supplementary equation is the space law conservation [5]. which is written:

$$
\frac{d}{d t}\left(\int_{Q(t)} d \Omega\right)=\int_{i=(r)} v_{j} d n_{j}
$$

The fluid problem is then fully characrerized by Eqs. (5) to $(7)^{2}$. Additional boundary conditions are to be taken into account such as imposed pressure or velocity. The coupling with the structure problem is expressed as $\left.\frac{\partial \mathbf{u}}{\partial t}\right|_{\Gamma}=\left.\mathbf{v}\right|_{\mathrm{r}}$. where $\mathbf{u}$ is the structu e displacement and $r$ is the fluid-structure interface.

\footnotetext{
2 In the case of a compressible fluid, the fluid state law $\rho(p)$ allows a classure of the problem.
} 


\subsection{Discretization of the structure problem: finite element}

Space discretization of the structure problem is carried out using two nodes beam finite element with linear shape functions for traction-compression $"$ and cubic shape functions for flexion $v$ (see Fig. 3)

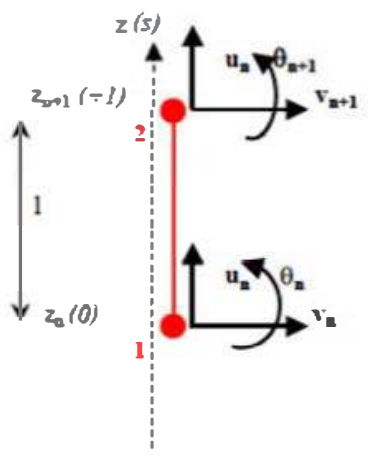

Figure 3. Beam finite element with two nodes, tbree degrees of freedom per node

Finite element discretization procedure leads to the following matrix system [18]:

$$
\left[\begin{array}{cc}
M_{u} & 0 \\
0 & M_{v}
\end{array}\right]\left\{\begin{array}{l}
\ddot{U} \\
\ddot{V}
\end{array}\right\}+\left[\begin{array}{cc}
K_{u} & 0 \\
0 & K_{v}
\end{array}\right]\left\{\begin{array}{l}
U \\
V
\end{array}\right\}+\left\{\begin{array}{l}
R_{u}(V) \\
R_{v}(U)
\end{array}\right\}=\left\{\begin{array}{c}
0 \\
\Phi_{v}
\end{array}\right\}
$$

where the mass matrices are given by $\left[M_{3}\right]=\int_{0}^{2} \rho_{5} s\left\{N_{0} X_{N_{0}}\right\rangle$. and $\left.\left[M_{v}\right]=\int_{0}^{I} \rho_{s} s\left\{N_{v}\right\} N_{v}\right\}$. the stiffness matrices are expressed as $\quad\left[K_{u}\right]=\int_{0}^{L} E S\left\{\frac{\partial N_{u}}{\partial z}\right\}\left\langle\frac{\partial N_{u}}{\partial z}\right\rangle \quad$ and $\left[K_{v}\right]=\int_{0}^{L} E I\left\{\frac{\partial^{2} N_{v}}{\partial \Sigma}\right\}\left\langle\frac{\partial^{2} N_{v}}{\partial \Sigma}\right\rangle$. and the loading vector is written $\left\{\Phi_{v}\right\}=-\int_{0}^{L} \rho_{5} S \gamma\left\{N_{v}\right\}+\Phi$ where $\Phi$ is the projection of fuid forces onto the structure finite element mesh (see next subsection).

The non-linear terms are:

$$
\begin{gathered}
\left\{R_{u}(V)\right\}=\int_{0}^{L} \frac{E S}{2}\left\{\frac{\partial N_{u}}{\partial z}\right\}\langle V\rangle\left\{\frac{\partial N_{v}}{\partial z}\right\}\left\langle\frac{\partial N_{v}}{\partial z}\right)\{V\} \\
\left\{R_{v}(U, V)\right\}=\int_{0}^{L} E S\left\{\frac{\partial N_{v}}{\partial z}\right\}\left[\left(\frac{\partial N_{u}}{\partial z}\right)\{U\}+\right. \\
\left.\left.\left.\frac{1}{2}\langle V\rangle\left\{\frac{\partial N_{v}}{\partial z}\right\}\left(\frac{\partial N_{v}}{\partial z}\right)\{V\}\right]\right\} \frac{\partial N_{v}}{\partial z}\right)\{V\}
\end{gathered}
$$

Mass and stiffness mattices are calculated analytically and non-linear terms are evaluated with numerical procedures.

\subsection{Discretization of the fluid problem: finite volume}

The general form of an integrated conservation equation for a fluid unknown $\phi$ is the following one:

$$
\frac{d}{d t}\left(\int_{\Omega(t)} \rho \phi d \Omega\right)+\int_{\alpha(t)} \rho\left(v_{j}-v_{j}^{*}\right) \phi d n_{j}=\int_{\Omega(t)} S_{\phi} d \Omega+\int_{\alpha \Omega(t)} \Gamma \frac{\partial \phi}{\partial x_{j}} d n_{j}
$$

Equation (11) is discretized using a finite volume method. The fluid domain is divided in elementary fluid cells. for uhich an integrated conservation equation is uritten. Figure 4 gives a typical representation of a computational grid for a 2D Cartesian problem.

A moving mesh technique is used: the elementary grid velocity is deduced from known node displacement in order to satisfy Eq. (7) [8]: The grid velocity $v_{i}{ }^{*}$ appearing in the right side of Eq. (7) becomes then a source term on the left-hand side. Integrated conservation equations are written for each cell: $P$ is the cell center. WW.W.SW.S.SE.E.EE.NE.N are the centers of neighboring cells.

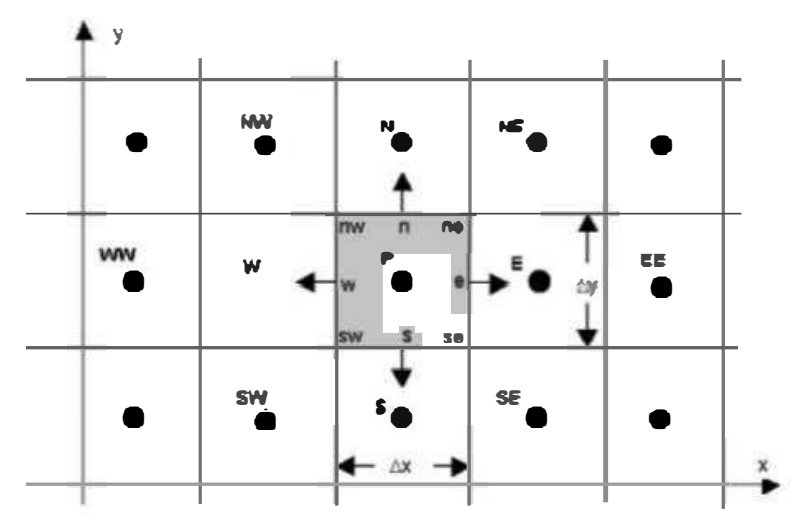

Figure 4. 2D fluid computational grid

The time dependant in Eq. (11) are approximated by an EULER scheme. i.e. Writing:

$$
\frac{d}{d t}\left(\int_{\Omega(n)} \rho \phi d \Omega\right) \approx \frac{\rho \Omega}{\delta t}\left(\phi_{p}^{n+1}-\phi_{P}^{n+1}\right)
$$

The convective and diffusive terms are calculated using finite difference approximation. leading to the global expression [8]: 


$$
\int_{\Omega_{p}(z)} \rho v_{j} \phi-\Gamma \frac{\partial \phi}{\partial x_{j}} d n_{j} \approx \sum_{\Downarrow} C_{M}^{*-1} \phi_{M}^{n+1}-D_{M}^{n+1} \phi_{M}^{n+1}
$$

where $M$ stands for the neighboring points of cell $\Omega_{P}$.

Taking into account Eqs. (12) and (13) leads to the following algebraic non-linear system $[A(\phi)]\{\phi\}=\{b\}$. that is:

$$
A_{P} \phi_{P}^{a+1}=\sum_{\underline{\underline{u}}} A_{P} \phi_{P}^{n+1}+b_{P} \phi_{P}^{n}
$$

From discretization practices presented abore, it is possible to produce the following algebraic system resulting from the finite volume discretization of the momentum equation and POISSON equations:

$$
\begin{aligned}
& A_{p} v_{i, p}^{n-1}=H\left(v_{i}^{n-1}\right)+D\left(p^{n-1}\right)+S_{v_{j}}^{\infty-1} \\
& A_{p} p_{p}^{n+1}=G\left(p^{n+1}\right)+S_{p}\left(v_{1}^{n+1}\right)
\end{aligned}
$$

Equations (15) and (16) couple the pressure and velocity unknowns. An implicit iterative scheme is used to calculate the new values of the velocity and pressure field [11]. The algorithm starts with an estimation of the velocity field. by solving the following non-linear system. obtained from Eq. (15) by using the pressure field computed at the previous time step:

$$
A_{P} v_{i, P}^{n+1,(0)}=H\left(v_{i}^{n+1,(0)}\right)+D\left(p^{n}\right)+S_{v_{i}}^{n+1}
$$

Equations (15) and (16) are then used to produce successive correction. by using the iterative relations:

$$
\left\{\begin{array}{c}
A_{p} v_{i, p}^{n+1,(q+1)}=H\left(v_{i}^{n+1,(q)}\right)+D\left(p^{n+1,(q)}\right)+S_{v_{i}^{n+1}}^{n+1} \\
A_{p} p_{P}^{n+1,(q)}=G\left(p^{n+1,(q)}\right)+S_{p}\left(v_{i}^{n+1,(q)}\right)
\end{array}\right.
$$

The iterative scheme is stopped when a convergence criterion is satisfied or when a maximum number of inner iterations is reached.

From the practical point of view. the coupled problem is solved using the CFD code Star-CD [22]. which allows the numerical calculation for the fluid problem part. The stucture problem part is solved using FORTRAN subroutines developed within the CFD code.

\section{COUPLING PROCEDURE}

The key of the numerical method for the coupled problem lays in the coupling procedure between the fluid and structure codes.
The coupling procedure allows coupling the problems:

$\checkmark$ in space:

$\checkmark$ in time.

\subsection{Coupling in space}

The space coupling procedure handles numerical exchanges between the fluid and structure problems. Structure displacement are transferred from the structure mesh to the fluid mesh. and fluid forces are projected from fluid boundaries to structure mesh. as sketched by Fig. 5 .

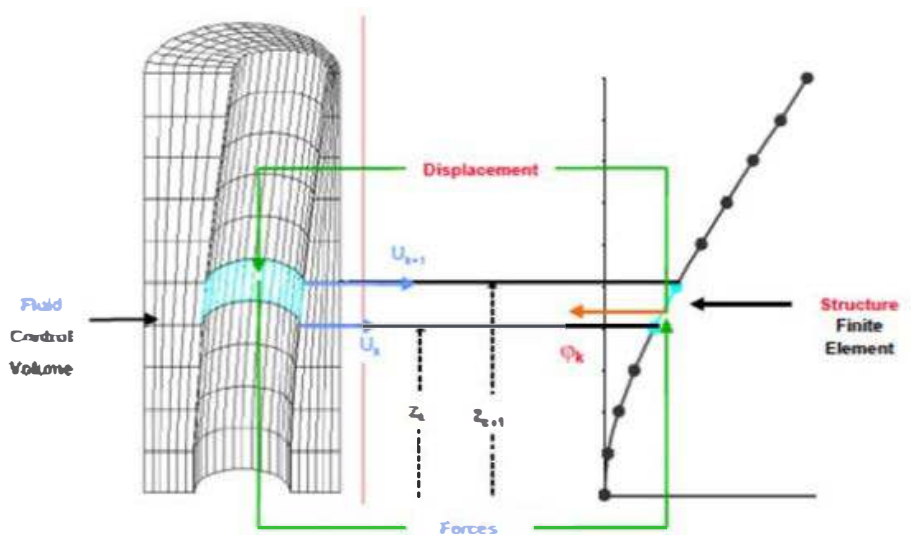

Figure 5. FE structure code and FV fluid code space coupling

As fluid and structure meshes can be very different (a few finite element are enough to describe the structure dynamic. an important number of fluid finite volume are required to solve the fluid problem. with local refinement to describe boundary layer), the space coupling procedure uses interpolation tecluiques in the displacement/force exchanges between the two sub-problems [2].

Since the fluid problem is re-meshed at each time step to take into account structure deformation. the fluid finite volume can undergo great shape deformation. Many re-meshing coupling techniques can be dereloped to preserve the fluid mesh quality [19]. As the fluid geometry is rather simple in the present case. it is possible to develop a re-meshing procedure that produces little deformation of the fluid cells. based on a purely geometrical approach of the problem.

Figure 6 shows a 2D half slice of the fluid mesh. in the initial state and a deforned state: fluid cells length ratios are preserved even for large amplitude inner cylinder motion ${ }^{3}$.

\footnotetext{
${ }^{3}$ For wen large displocemens, ic. when the inner cylinder alinost comes unso contacs with the ouser one, she proposed re-meshing techique will foil forher ones roo !...) io preserie mesh gualin. bi this case, a numejical rechnigue based on birthdeosh fiuid cells opproach would be iscful. Such a method is atailable in the STAR-CD cade [2]] and is currenth imestigated in the present coupled problen.
} 

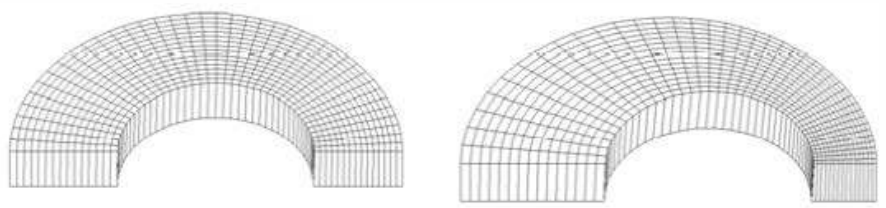

Initial mesh

Figure 6. Initial and deformed mesh

\subsection{Coupling in time}

Coupling in time can be carried out using either explicit or implicit approaches. In a previous paper, the elementary case described by Fig. I has been studied with explicit coupling procedure (see SIGRIST et al. [18]). The purpose of the present study is to apply implicit coupling procedure, using the fluidrigid body implicit method developed by AB०uRI et $a /[1]$.

A rigid-body movement is described by a set of ordinary differential equations of the form:

$$
\left\{\begin{array}{l}
m \frac{d \dot{\mathbf{X}}}{d t}=F(\dot{\mathbf{X}}, x, t) \\
\frac{d \mathbf{X}}{d t}=\dot{\mathbf{X}}
\end{array}\right.
$$

where $\mathbf{X}$ and $\dot{\mathrm{X}}$ are the displacement and velocity of the solid system.

Equation (19) can be solved using an explicit step by step method. A first order numerical scheme is for instance:

$$
\dot{\mathbf{X}}_{n+1}=\dot{\mathbf{X}}_{n}+d t \frac{F\left(\dot{\mathbf{X}}_{n}, x_{n}, t_{n}\right)}{m}
$$

Such a method has been previously used to peiform numerical simulation of the generic coupled case [18]. The explicit approach is rather straightforward, in particular with nonlinear problems.

However, stability problems are likely to occur while using explicit schemes. Implicit time discretization can be used to overcome such difficulty. A first order implicit approximation of Eq. (19) reads:

$$
\dot{\mathbf{X}}_{n+1}=\dot{\mathbf{X}}_{n}+\frac{d t}{2}\left(\frac{F\left(\dot{\mathbf{x}}_{n}, x_{n}, t_{n}\right)+F\left(\dot{\mathbf{X}}_{n+1}, x_{n+1}, t_{n+1}\right)}{m}\right)
$$

The following non-linear system has then to be solved to calculate $\dot{\mathrm{X}}_{n+1}$ :
$\psi\left(\dot{\mathbf{X}}_{n+1}\right)=v_{n+1}-v_{n}-\frac{d t}{2}\left(\frac{F\left(\dot{\mathbf{X}}_{n}, x_{n}, t_{n}\right)+F\left(\dot{\mathbf{X}}_{n+1}, x_{n+1}, t_{n+1}\right)}{m}\right)=0$

As it is well known, in order to accelerate convergence the most widely used and most robust method for the solution of non-linear system is Newton-Raphson method. It requires the evaluation of derivatives that are approximated by finite differences. Solving $\psi\left(\dot{\mathbf{X}}_{n+1}\right)=0$ is performed with the following iterations:

$$
\left.\dot{\mathbf{X}}_{n+1}^{(k)}=\dot{\mathbf{X}}_{n+1}^{(k}{ }^{1)}-\left[\nabla \psi\left(\dot{\mathbf{X}}_{n+1}^{(k} 1\right)\right)\right]{ }^{1} \psi\left(\dot{\mathbf{X}}_{n+1}^{(k l)}\right)
$$

The iterative procedure starts with the initial value $\dot{\mathbf{X}}_{n ! l}^{0}$, which can be predicted by an explicit scheme of the same order or simply from the result of the last time step $\left(\dot{\mathrm{X}}_{n+1}^{0}=\dot{\mathrm{X}}_{n}\right)$.

In the studied case, the structure equation - see Eq. (8) - is written:

$$
\mathbf{M} \ddot{\mathbf{X}}+\mathbf{K}(\mathbf{X}) \mathbf{X}=-\mathbf{M D} \gamma+\boldsymbol{\Phi}
$$

where $\gamma$ is the imposed shock in direction $\mathbf{D}$ and $\mathbf{D}$ is the fluid force. Implicit discretization of Eq. (24) also leads to a non-linear problem $\psi\left(\dot{\mathbf{X}}_{n+1}\right)=0$, which is solved with the algorithm described by Fig. 7 bellow. At each time step, the procedure proceeds as follows.

1. Initialisation of structure displacement $\mathbf{X}_{n+1}^{0}=X_{n}$, and velocity $\dot{\mathrm{X}}_{n+1}^{0}=\dot{\mathrm{X}}_{n}$, of structure pressure $p_{n+1}^{0}=p_{n}$ and velocity $\mathbf{v}_{n+1}^{0}=\mathbf{v}_{n}$, of fluid mesh $\Omega_{n+1}^{*}=\Omega_{n}$ and fluid furces $\boldsymbol{\Phi}_{n+1}^{0}=\boldsymbol{\Phi}_{n}$.

2. Structure calculation (with finite element discretization) by solving Eq. (23) to obtain $\dot{X}_{n+1}^{(k)}$ and then $X_{n+1}^{(k)}$.

3. Coupling in space to fluid problem. Fluid mesh $\Omega_{n+1}{ }^{(k)}$ and fluid boundary condition at $\Gamma_{n+l}{ }^{(k)}$ are deduced from structure displacement and velocity.

4. Fluid calculation (with finite volume discretization) by solving Eq. (14) with the PISO algorithm.

5. Coupling in space to structure problem. Fluid forces acting on $\boldsymbol{\Phi}_{n+1}{ }^{(k)}$ are projected to the structure mesh. 
6. Coupling in time between the two problems by performing a convergence test on structure displacement $\left\|\mathbf{X}_{n+1}^{k}-\mathbf{X}_{n+1}^{k}\right\| \leq \varepsilon$. If the convergence criterion is satisfied. the coupling loop ends: otherwise. calculation proceeds uithin the coupling loop.

Coupling iteration are performed with the same time step we used a restant recluuique for moving mesh problems automated with an operating system script.

When convergence criterion is not taken into account. the algorithm is equivalent to an explicit coupled procedure. Explicit and implicit approaches can then be easily compared.

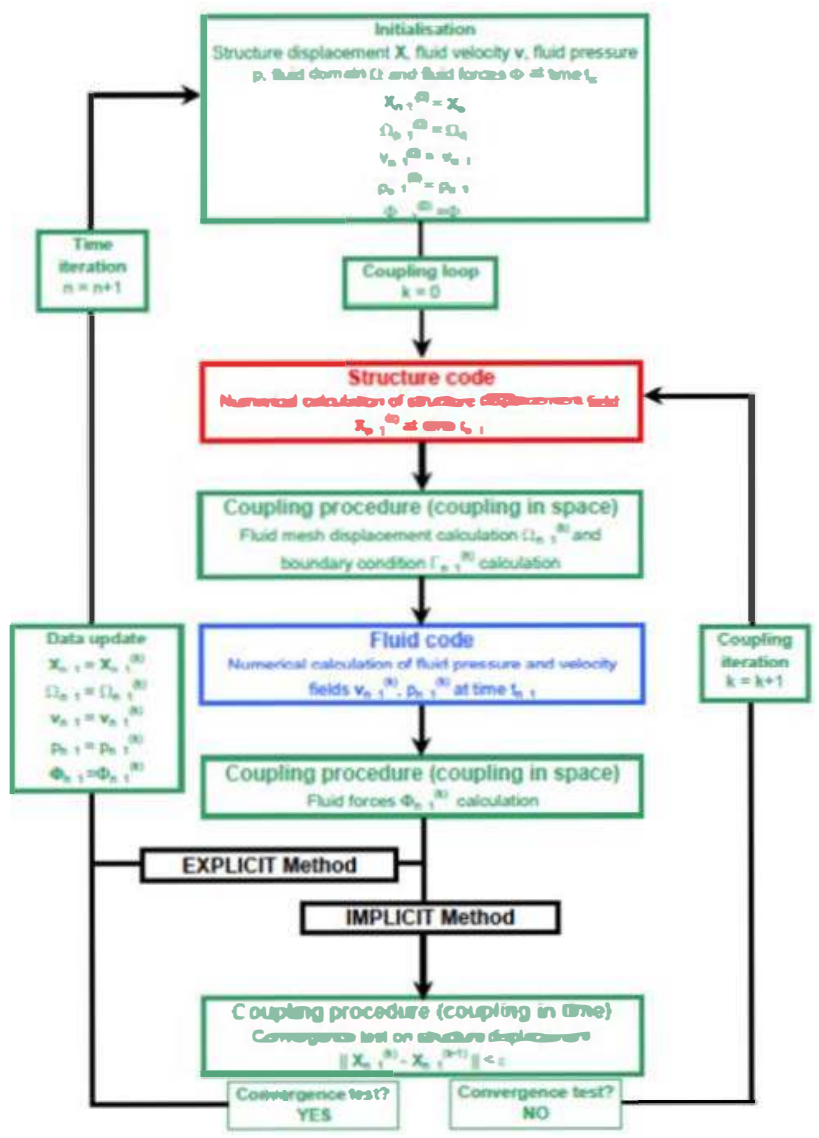

Figure 7. Explicit and implicit coupling method

\section{APPLICATION EXAMPLES}

Explicit and implicit coupling procedures are tested on two application examples.

\subsection{Fluid-cylinder coupled problem}

First application is a fluid-rigid problem. as defined by Fig. 8. Free oscillations of the rigid cylinder are given by $u(t)=\|_{0} \cos \left(2 \pi \delta_{h} t\right)$ with $f=\frac{1}{2 \pi} \times \sqrt{\frac{k}{m+m_{h}}}$ where $m_{h}$ is the fluid added mass [9].

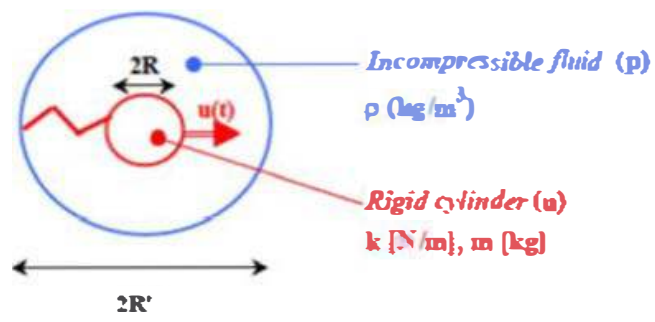

Figure 8. Rigid cylinder oscillating in a confined non viscous fluid

Table 1 gives the numerical value used for numerical simulations.

\begin{tabular}{cc}
\hline Paramete1 & Value \\
\hline \hline $\mathrm{R}[\mathrm{m}]$ & 0.1 \\
$\mathrm{R}^{\circ}[\mathrm{m}]$ & 0.2 \\
$\mathrm{~h}[\mathrm{~m}]$ & 0.01 \\
$\mathrm{k}[\mathrm{N} \mathrm{m}]$ & 60 \\
$\mathrm{~m}[\mathrm{~kg}]$ & 1 \\
$\mathrm{~m}_{\mathrm{b}}[\mathrm{kg}]$ & 0.52 \\
$\mathrm{f}_{0}[\mathrm{kz}]$ & 1.233 \\
$\mathrm{f}_{\mathrm{b}}[\mathrm{hz}]$ & 1.000 \\
\hline
\end{tabular}

Table 1. Fluid-cylinder problem

Figure 9 gives the numerical results for the cylinder free oscillations and compares the analytical solution to the numerical solution obtained with the explicit method for time steps $d t=0.01 \mathrm{~s}$ and $d t=0.001 \mathrm{~s}$ and with the implicit method for time step $d t=0.01 \mathrm{~s}$.

Figure 10 gires the number of inner coupling iterations during the simulation.

These results illustrate the numerical properties of explicit and implicit prosedures:

$\checkmark$ explicit coupling iotrutuces a numerical damping that can be decreased using a smaller time steps.

$\checkmark$ implicit coupling is free of numerical damping eten when large time steps are used. Although implicit coupling with $d t=0.01 \mathrm{~s}$ requires an average number of inner iteration around 5. computation time is still lower than in the case 
of explicit coupling with $d t=0.001 \mathrm{~s}$. for equivalent results.

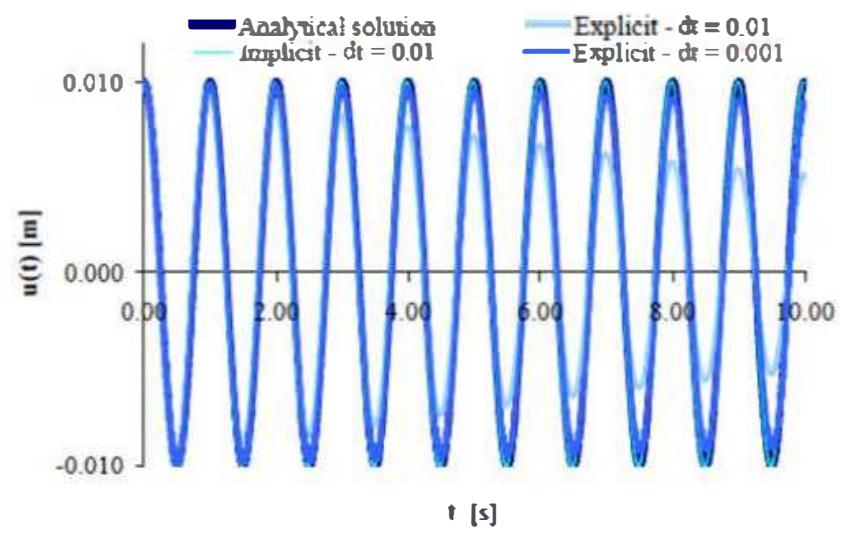

Figure 9. Free oscillation calculation. Cylinder displacement

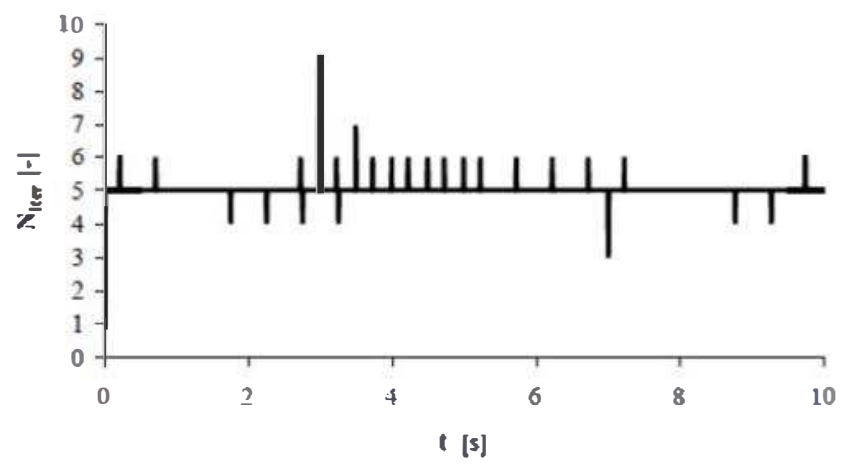

Figure 10. Free oscillation calculation. Coupling iterations

\subsection{Fluid-beam coupled problem}

Second application is the fluid-bean coupled problem defined by Fig. 2. The whole system is subjected to a sine wave acceleration:

$$
\gamma(t)=\left\{\begin{array}{ccc}
\gamma \times \sin \left(2 \pi \frac{t}{\tau}\right) & \text { if } & 0 \leq t \leq \tau \\
0 & \text { if } & \tau<1
\end{array}\right.
$$

Geometry and physical parameters of the problem are given in Tab. 2.

Calculations are performed using explicit and inplicit algorithms.

\begin{tabular}{cc}
\hline Parameter & Value \\
\hline$R[\mathrm{~m}]$ & 0.1 \\
$\mathrm{~L}[\mathrm{~m}]$ & 1 \\
$\mathrm{e}[\mathrm{m}]$ & 0.02 \\
$\rho_{S}\left[\mathrm{~kg} \mathrm{~m} \mathrm{~m}^{3}\right]$ & 7800 \\
$\mathrm{E}[\mathrm{Pa}]$ & $6.0410^{8}$ \\
$\mathrm{R}^{\prime}[\mathrm{m}]$ & 0.2 \\
$\mathrm{H}[\mathrm{m}]$ & 1 \\
$\rho_{E}\left[\mathrm{~kg} \mathrm{\textrm {m } ^ { 3 }}\right]$ & 1000 \\
$\tau[\mathrm{s}]$ & 0.1 \\
$\gamma\left[\mathrm{m} \mathrm{s} \mathrm{s}^{3}\right]$ & 5 \\
\hline
\end{tabular}

Table 2. Fluid-beam problem

Figure 11 gives the relative displacement (in the moring frame) of the beam free end versus time in various conditions. Figure 12 gives the corresponding absolute acceleration. The numerical results are compared to a finite element computation. which is the reference case [18].

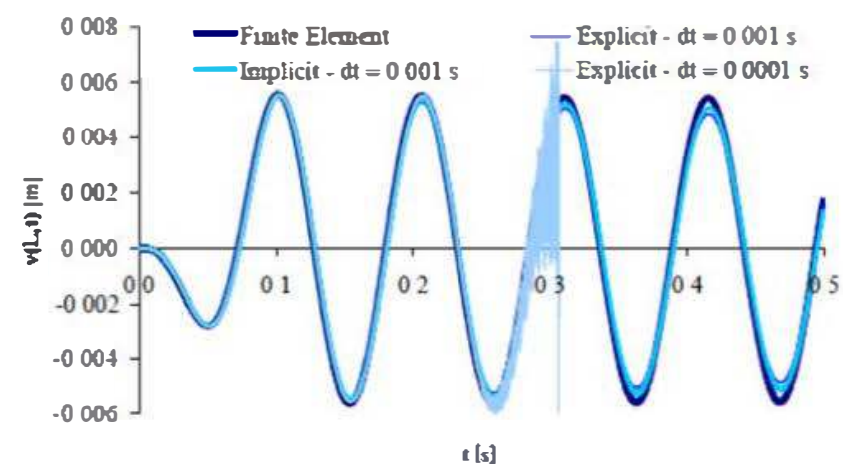

Figure 11. Shock calculation. Beam relative displacement

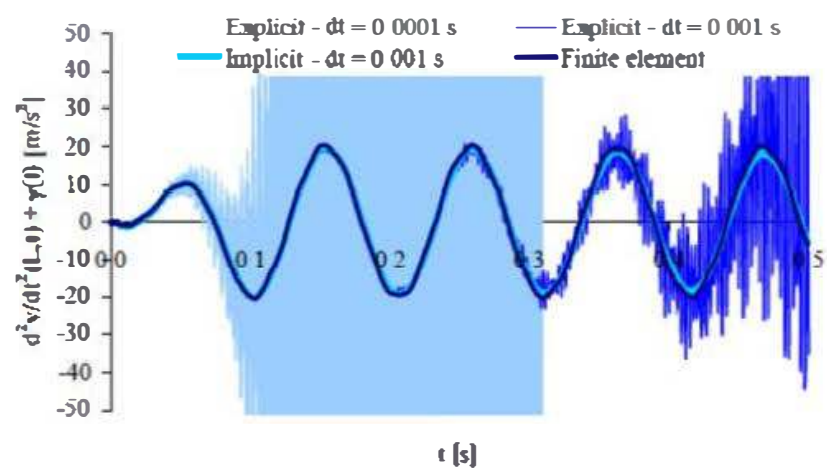

Figure 12. Shock calculation. Beam absolute acceleration

Nunerical results obtained with implicit coupling for $d t=0.001 \mathrm{~s}$ are in good agreement with the finite element calculation. both in terms of displacement and acceleration. 
The procedure is slightly numerically dissipative but remain numerically stable.

Computation with explicit coupling with the same time step seem to give equivalent results in terms of displacement. but the procedure is more dissipative and potentially unstable. as can be shown by acceleration calculation.

Numerical dissipation could be expected to be lowered in explicit coupling by using a smaller time step ( $d t=0.0001 \mathrm{~s}$ ) but this increases numerical instability.

Figure 13 gives the number of coupling iterations in the case of implicit coupling. The average number is around 3. the corresponding required computational time effort is by far compensated by the use of larger time steps.

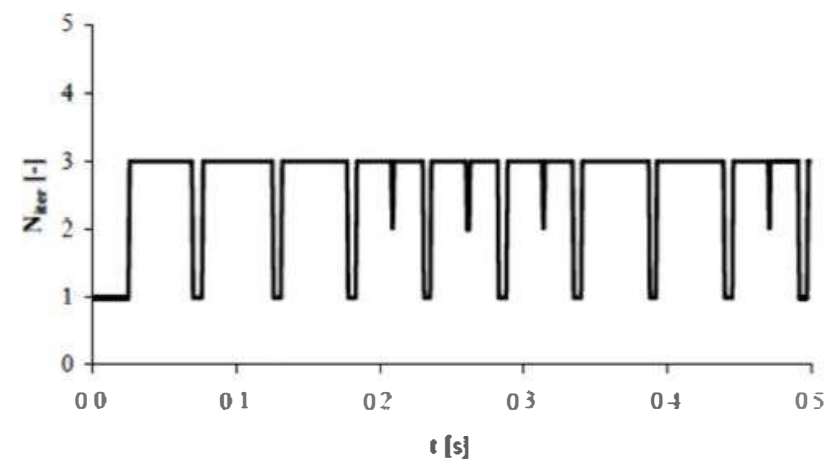

Figure 13. Shock calculation. Coupling iterations

These numerical results are a good illustration of the numerical properties of implicit coupling for non-linear fluidstructure coupled simulations.

\section{CONCLUSION}

Ant elementary study of coupled fluid-structure simulations by finite element-finite volume coupling using standard nunnerical tools has been proposed in the present paper.

The study focuses on tine coupling procedures. Explicit and implicit approaches are applied in a generic non-linear fluidstructure coupled test case, using a CFD code.

Implicit and explicit procedure are first recalled. Various calculation results are then exposed and compared from the mumerical points of view: dissipation and stability properies of the time coupling schemes are illustrated.

Industrial applications of the coupled techniques are currently under investigation in order to study flow induced vibrations phenomenon in tube bundle (following the studies of LONGATTE \& SOLL[3]).

\section{REFERENCES}

[1] D. ABOURI. A PARRI A HAMDOUTA. A. Srable Fluid Rigid Bods Interaction Algorithm Application 10 Industrial Prablems. Pressare Vessel and Pipug. San Diego. 25-29 July 2004

[2] A. BECKERT. Coupling Fluid (CFD) and Structural (FE) aodels Using Funte Interpolation Elements Aerospace Science and rechnology. 4 (1). 1322, 2000 .

[3] Z. Bendiedou, E. Longate. A. Adobes. M. Soull. Sieam Genarator Tube Vibrations Experimental deremination veriss LLE Computation of F7uidelestic Forces. Pressure Vessel and Pipmg. Cleveland. 20-24 July 2003.

[4] F. CAStDE. J.P. HaUEUX A S.LA. F. CROUE. Transiant Fluid Structure Inseraction Algorithm for I arge Indurvial Applications. Computer Mectods in Applied Mechanical Engineering 190, 3081-3110, 2001.

[j] I. DEIGRDZIC. $M$ PERIC Space Consenation law in Finite Volume Calculations of Fluid Elow. International Joumal for Numerical Methods in F7uids. 8. 1037-1050. 1988.

[6] MA DORIINist K SUBBiR-4. A Survey of Direct Time-Integuation Methods in Computational Dyranuics-I: Explicit Methods. Computer \& Structures. 32. 1371-1386, 1989.

[7] C. Farbat, M. Lesotnne N. Mlaran. Mixed Explicivimolicit Time Inicgration of Coupled Aeroelastic Problems. Iniennational Joumal of Numerical Meshods in Fluids, 21.807-835, 1995

[8] J.H Ferziger M PERIC. Compurational Merhods for Flujd Dinamics Springer-Verlag. 1999

[9] R.J. Ferr. The Effect of Liquids on the Droamic Motion of Immersed Solids. Jorrnal of Engineering for Industn'. 167-173, 1972.

[10] J. HiNO. Y. YOSHIRURA X. ANANTHANARtY.WA. Vibration Analysis of Non-Linear Beams Subjected to a Moring Load Uising the Finite Element Method. Journal of Sound and Vibrotion, 100, 477-491. 1985

[11] RI. Iss.t. Solution of The Implicitly Discretused Flund Flow Equation by Operator Spliting. Jormal of Compurational Phisics, 62 4065, 1985.

[12] E. DE LANGRE. F7uides et Solides. Les éditions de l'Ecole Polytechaique. 2002 .

[13] J. MusteruE. Fluid-Strustore Interaction Problems, Finite Element Approach and Boundary Elemrats Approaches. A Brbliography. Finise Elemerts in Analysis and Design, 31, 231-240. 1999.

[14] H. J.P. MORAN. R. OHAYON. Fluid Sinuctime Inseraction. Miley \& Sons. 1995

[15] J.M.T PENROSE. C.J. SI.APLS. Implicit Fluid-Serucnure Coupling for Simulacion of Cardiovascular Problems. International Journal for Nemerical Methods in Flurids, 1. 1-13. 2001.

[16] J. S.MRRAIE. A. HUERTA. J. DONEA Arbitrary Lograngian Eulerian Formulation for F7uid Multi-Rigid Bodies Interection Problems. Compunation Mechanics. New Iread and Applications, 1998.

[17] M SCHifrR. Coupled Fluid-Solid Problems Stmey on Numerical Approaches and Applications. Pressure Vessel and Piping Cleveland, 20-24 July 2003.

[18] J.F SIGRIST. C. LUINE. Numerical Simulation of a Nom-Linarr Corpled Fluid-Sinucrure Problam by. Explicit Finire Element Finire Volume Coupling. Pressure Vessel and Piping, Denver. 17-21 July 2005.

[19] R.MG So, Y. Lli, Y.G. LAI Mesh Shape Presenation for FlowInduced Vibrations Problems. International Mechanical Engineenng Congress and Exposition New orleans, 17-22 November 2002.

[20] K. SLBb2ry, M.A. DORHINAH. A Survey of Direct Time-Integration Methods in Cocmpurational Dynamics-II: Implicit Methods. Computer \& Snzictures. 32. 1387-1401. 1989.

[21] ZU.A WARSI Conseriation form of the Navier Stokes Equatuons in General Non Steady Coordmates. American institue of Aeronautics and Astronautics Josmal, 19, 240-242, 1980.

[22] STAR CD Mechadology-User Guide. CD Adapeo Group, 2003. 